\title{
“洗い”の現象に関する研究一IV. 赤色及び白色魚肉魚類の死後硬直について
}

\author{
野口栄三郎・ 山本常治 \\ (日本海区水産研究所)
}

\author{
Studies on the "Arai" Phenomenon (the Muscle \\ Contration Caused by Perfusing Water)-IV. \\ On the Rigor-Mortis of White Meat Fish and of Red Meat Fish. \\ Eizaburo Noguchi and Jyoji Yamamoto
}

\begin{abstract}
It is commonly believed that fish muscle rich in muscle pigment as like mackerel and sardine decays more rapidly than those of white meat fish such as carp or red-snapper. But, only few informations are available for their difference. In this conneciton, the present study is scheduled to find out, if possible, a difference of rigor mortis between the muscles of red and white meat fish. Mackerel was used as a model of red meat fish and carp and red-snapper as white one. Sample fish were treated in two ways; one was to cut off head immediately after catch and another was to put into death after heavy struggling. And the amount of $\Delta 7 \mathrm{P}-\mathrm{P}$, glycogen, SH group and muscle contraction caused by perfusing water for each sample were determined and results were shown in Figs. $1-5$.

Difference in the changes of these compounds due to the variety of fish was not significantly observed, but the struggling of the fish till the time of death appeared to give remarkable effect on biochemical changes in the muscle.

Therefore, the greater part of the freshness of commercial fish will depend on fishing method whether it involves the struggling or not at the time of catch.

If the amount of A.T.P., glycogen and $\mathrm{pH}$ value could be maintained in high level when fish were killed on board, the rigor-mortis might proceed similarly in red and white meat fish.
\end{abstract}

一般にサバの生き腐れと云われるように，イワシ，サバ，カッオのような赤色魚肉を有する魚類は，タイ またはスズキのような白色魚肉を有する魚類に比較して，極好て鮮度が低下し易く，早く磨敗すると云われ ている。しかしこのよ5な差異に関与る研究は極めて少くて，僅か大谷》に依つてカッオ，サバの上5な淘 游性の赤色德肉魚類は，ダイ，スズキの上うな白色魚類に比較して自己消化酵素作用が早く，これは各魚類 の生前の活動性に依るものであらと述べられている程度である。しかし死後硬直の期間, 即ち生きの良さ を保つ期間に於ても，果してこのよ5な差暴があるむのであるか不かの研究は殆んど行われておらないの で，死後硬直現象に於てむ，魚種に依るこのような差異があるか否かを，茾汲ひタイ，コイについて研究

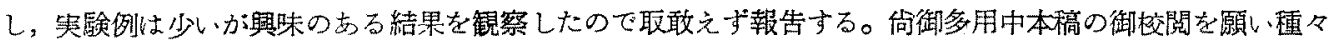
御教示を晹つた東海区办研右田博士，天野博士並びに本稿つ発表に御後援下さつた静岡県缶詰協会及び静 周県各位に厚く御礼を电上げる。

\section{実 験}

試料としてはコイ及び定置網で潐獲後 1 夜水族館の水槽内で蓄盖したタイ及びサバを使用しだ。死殺方法 は共に断頭死であるが，苦閶死区のるのは，サパは 10 分間，コイは 30 分間空気中に放置し，苦䦓させた 後断影死を行つて試料に供した。魚体は直らに3枚に卸し，大型シャーレーに入れて空温（タイ及びサバは

1955 年 2 月 28 日受理 (印殿费負担) 


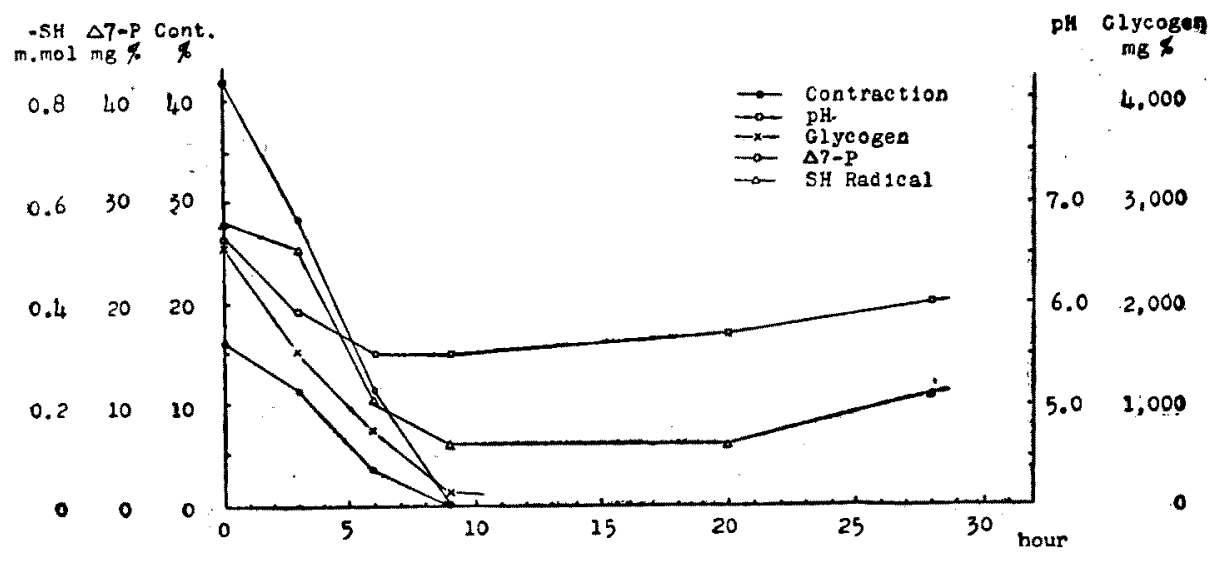

Fig. 1. Changes in contraction, $\mathrm{pH}$, glycogen, $\triangle 7 \mathrm{P}-\mathrm{P}$ and free $\mathrm{SH}$ group of the muscle of mackerel during storage at $20^{\circ} \mathrm{C}$., which fish was decapitated immediately after catch.

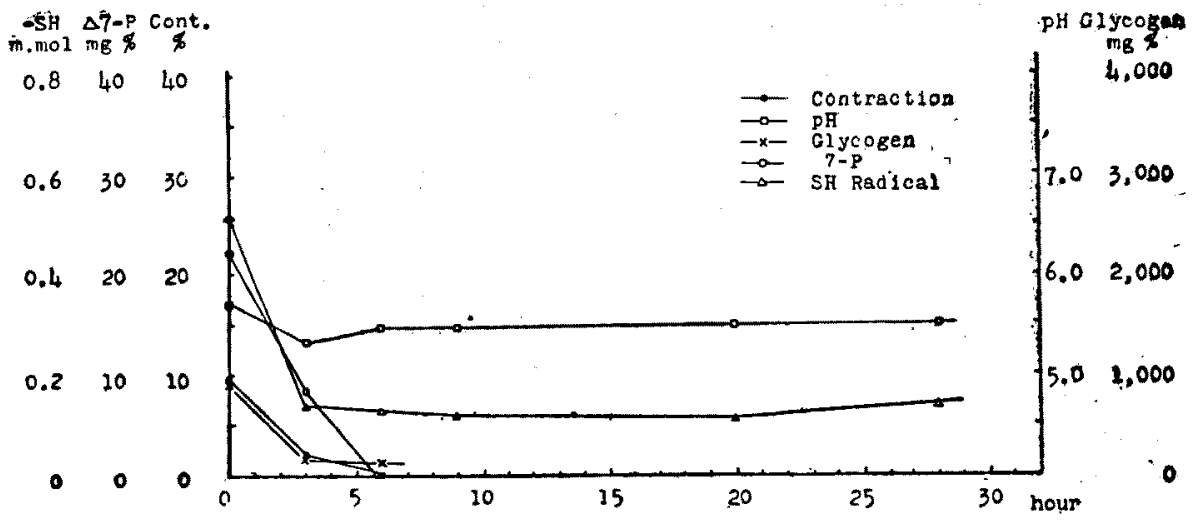

Fig. 2. Changes in contraction, $\mathrm{pH}$, glycogen, $\Delta 7 \mathrm{P}-\mathrm{P}$ and free $\mathrm{SH}$ group of the muscle of mackerel during storage at $20^{\circ} \mathrm{C}$, , which fish was decapitated after struggling.

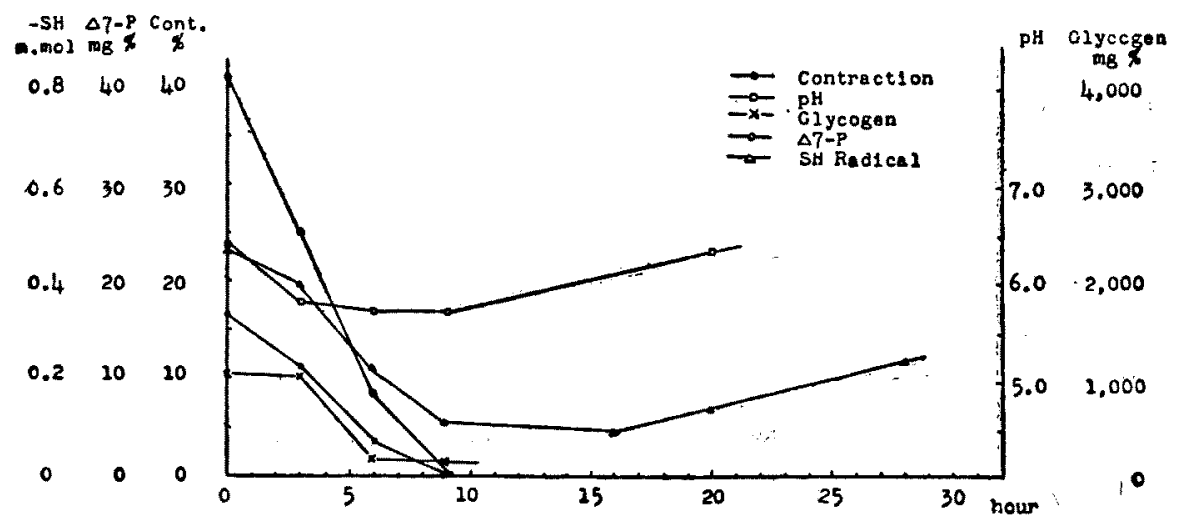

Fig. 3. Changes in contraction, $\mathrm{pH}$, glycogen, $\Delta 7 \mathrm{P}-\mathrm{P}$ and free $\mathrm{SH}$ group of the muscle of red-snapper during storage at $20^{\circ} \mathrm{C}$., which fish was decapitated immediately after catch. 


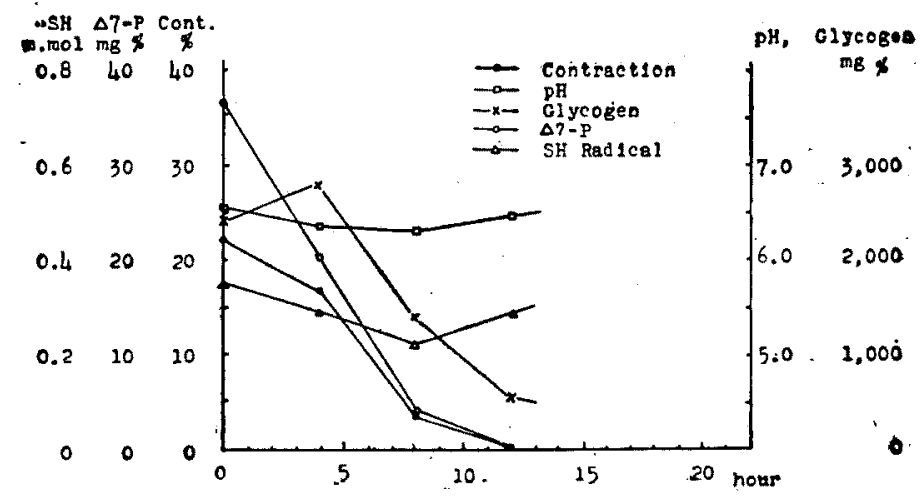

Fig. 4. Changes in contraction, $\mathrm{pH}$, glycogen, $\Delta 7 \mathrm{P}-\mathrm{P}$ and free $\mathrm{SH}$ group of the muscle of carp during storage at $30^{\circ} \mathrm{C}$., which fish was decapitated immediately after catch

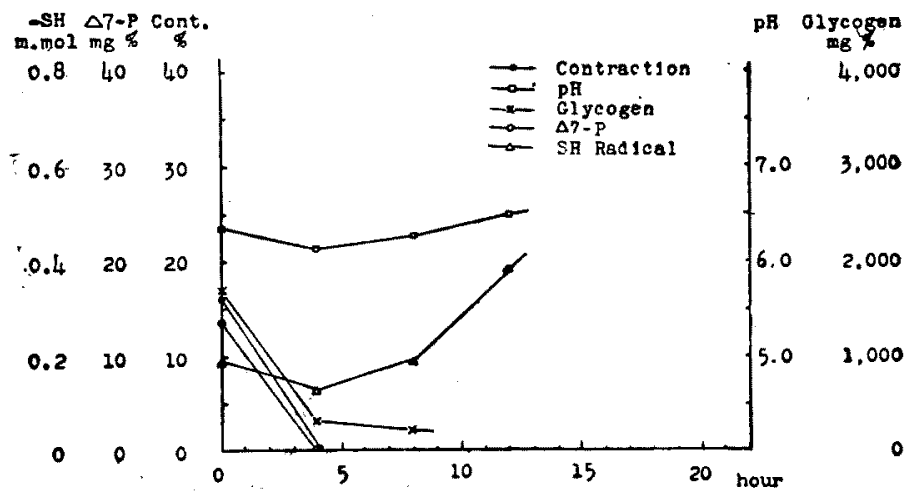

Fig. 5. Changes in contraction, pH, glycogen, $\Delta 7 \mathrm{P}-\mathrm{P}$ and free SH group of the muscle of carp during storage at $30^{\circ} \mathrm{C}$., which fish was decapitated after struggling.

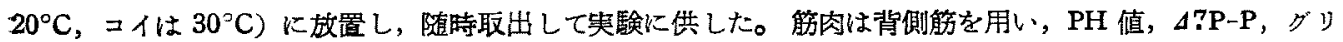
コーゲン量, 遊離 SH 基, “洗い”に依る筇肉の鏥み等は前報ると同様の方法で行つた。

結果

結果は第 1 図乃至第 5 図に示すようである。即ち直殺区に於けるサバヌびタイでは，“洗い”に依る縮み ATP 量, 遊離の SH 基等の変化では魚種に低る差異は少く，僅に $\mathrm{pH}$ 值及びダリコーゲンの減少速度が異 つて解然作用はサパの方が早い結果を示しているが，どちらも共に死後 9 時間内外で死後硬直が完了し，15

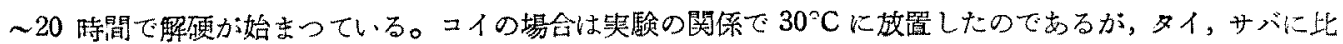
較して死後硬直の進行が遅く, 死後 12 時間で完了したように見点る。しかし実際には時閒の閒隔の取りうう

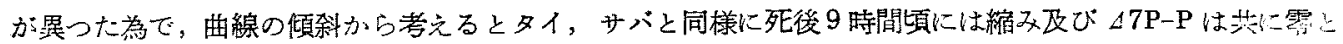

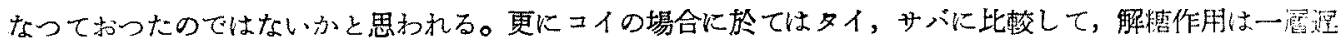
いことが覙察された。

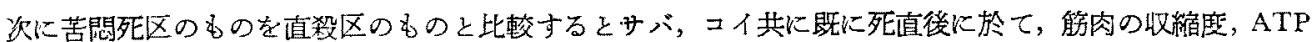
量, グリニーゲン量は甚だしく減少し，亲た筋肉の $\mathrm{pH}$ 值や遊離 $\mathrm{SH}$ 基の数も低い結果を示している。特

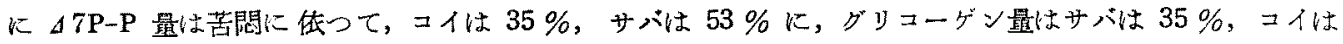
$60 \%$ に減少し, $\mathrm{pH}$ 值はサバは 6.4 から 5.7 に,コイは 6.5 から 6.1 と低下し, “洗い”に依る符肉の

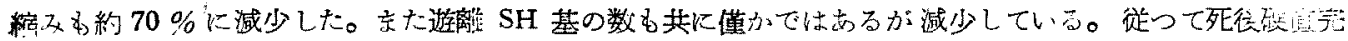

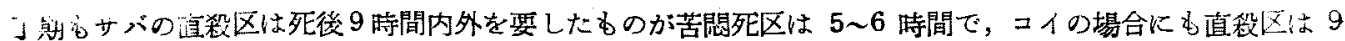


〜10 時閒であるのに対して，苦閔死区は4 時間以内と殆んど半分の時間で完了している。

\section{考}

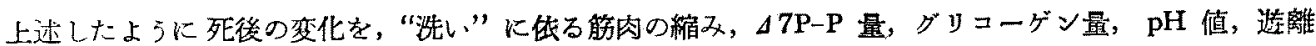

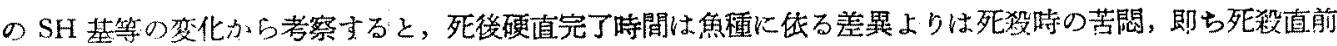
の激しい運動の力が強く影響し，魚種に依る美異は小さい。勿論死後に於ける解細作用は $\mathrm{pH}$ 值及びグリコ 一グンの隇少速度から考えて，サバが最も早くコイが最も遅い結果を示し，この影響が死後の ATP の減

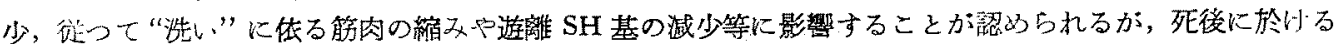

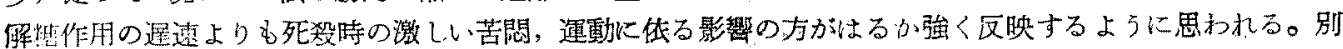

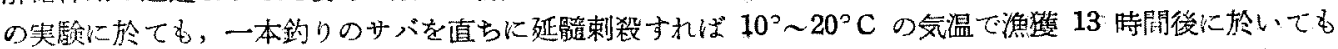
末だ肉色は透环で，“洗い”に倩る縮みやATP 全有量子多く，死後硬直完了前であつたのに対し，空気中 に放置し，苦悶に依つて死に到らしめたものは漁獲後 9 時間で既に解硬し軟化して篻食出来ず，死殺亦洼の

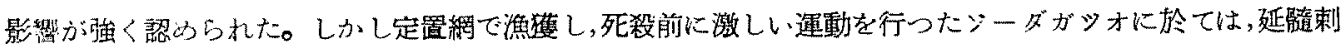
殺と自然死との間には余り顕著な差異が見られなかつた垁例るあつて, 死殺直前つ苦悶，運動の影響は極る て大きいと考兄られる。特にサバの場合はコイに比較して極めて短時間の苦悶であるのに $\mathrm{pH}$ の低下，グリ

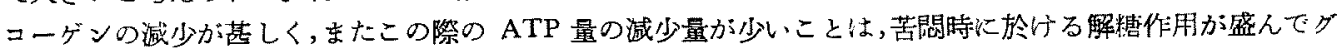
リコーゲンが消費ざれると同時火 ATP の再合成, 補給も盛んに行われるが, コイの場合には解粕作用が逮 く梴つてグリコーゲンの減少む少いが同時に ATP の再合成, 補給量も少いと考元ると,このような赤色魚肉 魚類の生活時の解糟作用は白色魚肉魚類に比較して旺盛であると云うように思われる。更に一般にサパ，力 ッオ,イワシの上うな赤色魚肉の魚類は漁蒦若くは羅網の際には極的て激しい運動学行うと共に，生前の筋 内肉のグリコーゲン量が多く, 且つ解糖作用も早いので, 死直後に於ける $\mathrm{pH}$ 值の低下が早く, 普通 6.0

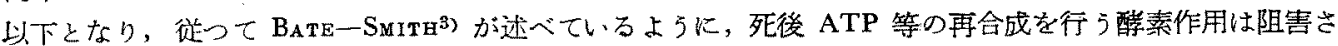
れ，無機燐酸に分解する醉素作用が促進されて急速に死後硬直が完了されることが予想される。一方白色急

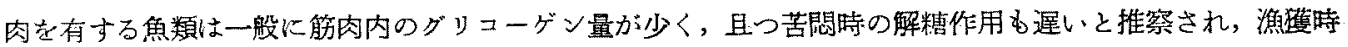

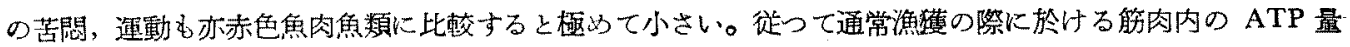
の消窟や $\mathrm{pH}$ 值の低下が小さく, $\mathrm{pH}$ 值も6.5 内外であるので死後に於いても ATP 等の再合成が行われ る可能性が多く，死後硬直への移行も比数的長時間を要するのであろうと考えられる。

即らこのような観点から赤色魚肉魚類と白色魚肉魚類の蘚度低下の速度が異る原因は肉晢本来の自己消化

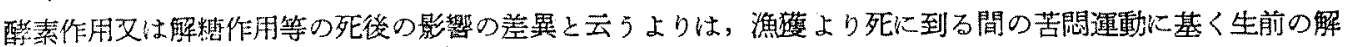

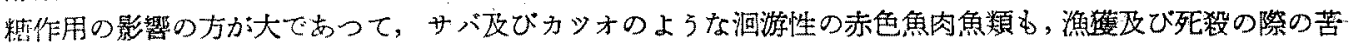
悶,運動を少くして, 筋肉内の $\mathrm{pH}$ 值, グリコーゲン量及び ATP の保持量等を高い状態で保持したま〉死 殺すれば，白色魚肉焦類である夕イ或はコイ等と殆んど異ることなく或る程度死後硬直期間を延長すること が出来，長時間生きの良さ丧保っことも可能であるよ5に思われる。

\section{还}

（1）臂度低下が早いと云われる赤色魚肉魚類と，そ5でない白色魚肉魚類の死後硬直期間の羑異を見る

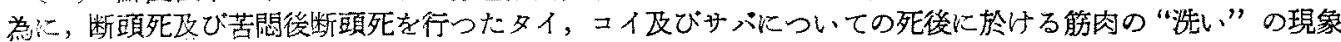
に依る縮み， $\triangle 7 \mathrm{P}-\mathrm{P}$ 量, グリコーゲン量, $\mathrm{pH}$ 值, 遊離 $\mathrm{SH}$ 基等の変化を比較した。

(2) 死後碩直時に於ける魚重に位るこ机らの变化の羛異は小さく，却って死殺前の苦悶，運動に依る影 響の力が極めて影く出現する。

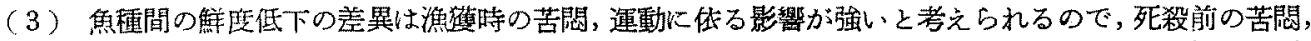

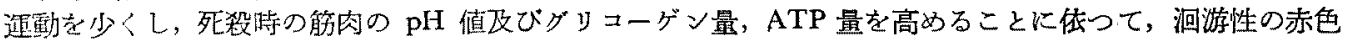

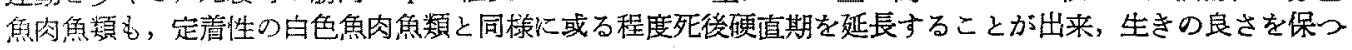
ことも可能であると考党られる。

\section{女献}

1）大谷武夫：水渞学会報，5，1928.

2) 野口栄三郎・山本常治：日水会誌, 20, 1020 2 (1955).

3) E.C. Bate-Smith and J.R. Bendali : J. Phisiol. 106, 177 185, (1947). 